\title{
Screening of different leaf extracts of Cassia fistula Linn for investigation of hypolipidemic activity in two different rat models
}

\author{
Guruprasad V. Sutar ${ }^{1}$, Kuntal Das ${ }^{2, *}$, John Wilking Einstein ${ }^{3}$ \\ ${ }^{1}$ Department of Pharmacology, Arvind Gavali College of Pharmacy, Jaitapur Post, Chinchner Vandan, \\ Dist. Satara, Maharashtra - 04, India \\ ${ }^{2}$ Department of Pharmacognosy and Natural Product Chemistry, Krupanidhi College of Pharmacy, \\ \#12/1, Chikka Bellandur, Carmelaram Post, Varthur, Hobli, Bangalore - 35, Karnataka, India \\ ${ }^{3}$ Department of Pharmacology, University of Malaya, Kuala Lumpur, Malaysia \\ *E-mail address: drkkdsd@gmail.com
}

\begin{abstract}
The present investigation was carried out to evaluate the hypolipidemic activity of methanolic and aqueous leaf extracts of Cassia fistula (CF) Linn (Family: Fabaceae) on atherogenic diet (2\% cholesterol, 1\% Choline Chloride and 2\% Lard) induced Male Sprauge-Dawley rats for the period of 21 days. The rats receiving the treatment with leaf methanol and aqueous extract of CF showed significant $(\mathrm{P}<0.001)$ reduction in total cholesterol $(\mathrm{TC})$, triglycerides $(\mathrm{TG})$, High density lipoprotein (HDL), lipid peroxidation (LPO) and other parameters at dose dependent manner but the effect was less than the standard drug Atorvastatin. The results revealed the effectiveness of CF plant against hyperlipidemic activity.
\end{abstract}

Keywords: Cassia fistula; Hypolipidemic effect; Cholesterol; Serum level

\section{INTRODUCTION}

In the recent era, diet containing high saturated fats and cholesterol, age, family history, hypertension and life style play a significant role in causing heart failure and the rate of heart failure has increased day by day. People with coronary disease develop thickened or hardened arteries in the heart muscle that lids to chest pain, a heart attack, or both (Harikumar et al., 2013). Because of these risks, treatment is often recommended for people with hyperlipidemia (Gupta and Jain, 2009). Generally synthetic allopathic hypolipidemic drugs are available at large in the market but the side-effects and contraindications of these drugs have marred their popularity and hence herbal hypolipidemic drug molecules have gained importance to fill the lacunae created by the allopathic drugs (Arun et al., 2004) by lowering blood lipid profile. Therefore plant originated natural products are the alternate possible therapeutic measure that became a subject of active scientific investigation due to presence of large number of active phytoconstituents which offer themselves as promising drug molecules for the development of huge number of medicinal activities that produce a significant physiological action on the human health (Das, 2014). 
Oflate, CF (Family: Fabaceae) is a plant which is commonly known as golden shower and has been used in the treatment of various ailments dating back to 'Charaka Samhita' and 'Sushruta Samhita'. Traditionally, various parts of CF are revealed in curing various diseases like cardiac disorders, diabetes, skin diseases and snake bite (Kirtikar and Basu, 1933) not only that the plant is also effective against liver troubles, tuberculous glands and its use in the treatment of haematemesis, pruritus, leucoderm and diabetes (Dutta and De, 1998).

The plant has scientifically documented to possess analgesic (Sheikh et al., 2010), antiinflammatory (Ilavarasan et al., 2005), antioxidant (Luximon-Ramma et al., 2002), antidiabetic, hypolipidemic (el-Saadany et al.,1991) as well as hepatoprotective activity (Bhakta et al., 2001), antibacterial and antifungal (Duraipandivan and Ignacimuthu, 2007) activities. The effect of ethanolic extract of CF legume was assessed on serum lipid metabolism in cholesterol fed rats (Gupta and Jain, 2009) not only that, the plant also possess hypolipidemic activity of Cassia fistula Legume and bark but no such reports on leaf extract of CF for treatment against hyperlipidemia. Therefore the present study has under taken to determine the effect of various extracts of CF leaf against hyperlipidemic activity in In vitro and In vivo models.

\section{MATERIALS AND METHOD}

\section{Standard drug}

Atorvastatin was procured from Biocon lab, Bangalore as a free sample for research purpose. Drug was dissolved in $2 \%$ Tween 80 to obtain a concentration of $10 \mathrm{mg} / \mathrm{Kg}$ bw (Hirunpanich et al., 2006).

\section{Other chemicals}

Cholesterol was purchased from Spectrochem Pvt Ltd, Mumbai, Choline Chloride from Bangalore Fine Chemicals, Thiobarbituric acid from Spectrochem Pvt Ltd, Mumbai, Trichloroacetic acid from Bangalore Fine Chemicals, $\mathrm{NaCl}$ and Tween 80 from Merck, formalin from Qualigens, Diethyl ether from Nice chemicals. Serum HDL diagnostic kit, Serum TC diagnostic kit and Serum TG diagnostic kit used in the study was purchased from Erba Diagnostics. Other chemicals and reagents were of analytical grade.

\section{Collection and Authentication of drug}

CF leaves of the plant were collected from Chandgad Dist, Kolhapur, Maharashtra. The plant was identified and authenticated by Dr. Shiddamallaya N, National Ayurveda Dietetics Research Institute, Bangalore, and the leaf specimen was preserved in Pharmacognosy department of St. John's Pharmacy College, Bangalore.

\section{Preparation of extracts}

The leaves of the plant were shade dried thoroughly till it loses all its moisture and then powdered. About $400 \mathrm{gm}$ coarse powders were separately used for methanol and aqueous extracts. Two different methods were used for the extraction, namely soxhlet method for methanol extract and simple hot maceration for aqueous extract. After complete extraction, the extract was filtered and the solvent was evaporated using rotary flash evaporator at $45^{\circ} \mathrm{C}$. Then it was concentrated to yield a semi solid residue of crude extracts. The yield was calculated and preliminary chemical tests were performed for identification of the presence of 
active constituents. Both the extracts were preserved separately under refrigeration condition at $5^{\circ} \mathrm{C}$ in air tight glass bottle for further investigation.

\section{Acute oral toxicity}

Acute oral toxicity studies were performed as per OECD guideline 423 for both the CF methanol extract (MECF) and aqueous extracts (AECF) and as per the toxicity level the doses has fixed.

\section{Standardization of Atherogenic diet (AD) induced hyperlipidemia}

The diet composed of 2\% cholesterol, 1\% Choline Chloride and 2\% Lard (Parini et al., 2000; Xu et al., 2009) was given to one group and another group was fed with normal pellet diet for 30 days. Male SD rats were used. Blood samples were collected on every seventh day till 30th day. The duration for feeding animals AD to induce hyperlipidemia for the actual study was decided based on this pilot study where significant elevated serum TG and TC values were obtained on 21 st day compare to normal group. Hence the actual study was later conducted for 21 days.

\section{Experimental Animals}

In-house laboratory bred healthy male SD rats with body weight of 200-220 gm, were used for the present experiment. They were housed, three per polypropylene cage under standard laboratory conditions at room temperature $\left(25^{\circ} \mathrm{C} \pm 2^{\circ} \mathrm{C}\right)$ with $12 \mathrm{~h}$ light /dark cycle and provided balanced pallet diet (Lipton India Ltd. Bangalore, India) and water ad libitum. The study protocol was approved by Institutional Animal Ethics Committee (IAEC), St. John's Pharmacy College, Bangalore (Proposal no. IJAHSM/IAEC/M-22/2011-2012). The rats were randomly divided into following groups each having 6 rats:

\begin{tabular}{|c|c|}
\hline Groups & Treatment \\
\hline Group 1 & Control group treated with saline solution \\
\hline Group 2 & Fed with (AD) \\
\hline Group 3 & Fed with AD + Atorvastatin @ $10 \mathrm{mg} / \mathrm{kg}$ \\
\hline Group 4 & Fed with AD + MECF @ 200 mg/kg \\
\hline Group 5 & Fed with AD + MECF @ 400 mg/kg \\
\hline Group 6 & Fed with AD + AECF @ 200 mg/kg \\
\hline Group 7 & Fed with AD + AECF @ 400 mg/kg \\
\hline
\end{tabular}

\section{Estimation of biochemical parameters}

On day 22nd, animals were anaesthetized with diethyl ether and blood was collected by retro orbital puncture. 
The blood was allowed to clot for $30 \mathrm{~min}$ at room temperature and then was subjected to centrifugation at $2000 \mathrm{rpm}$ for 15 minutes to obtain serum (Xu et al., 2009).

The resulting upper serum layer was collected in clean, dry and labeled microcentrifuge tubes and was analyzed for serum TC and TG by Quinoneimine dye absorption method at $505 \mathrm{~nm}$ described by Allain et al., 1974 and Fossati and Prencipe 1982 respectively, and HDL by precipitation with phosphotungstic acid and Magnesium chloride, described by Burstein et al., 1970.

Finally, the rats were sacrificed by cervical dislocation. Livers were perfused with normal saline to remove blood and then dried and weighed. Liver homogenate $(10 \%)$ was prepared using $0.9 \%$ saline by homogenizing with tissue homogenizer.

This homogenate was centrifuged at $7000 \mathrm{rpm}$ for $15 \mathrm{~min}$. The supernatant was collected and used for the estimation of lipid peroxidation (LPO) by taken absorbance at 535 nm, described by Ohkawa et al., 1979.

\section{Statistical analysis}

The data obtained by the various parameters was statistically evaluated by one way analysis of variance (ANOVA) followed by Dunneet's Multiple Comparison Test by Graph Pad Prism software (GraphPad software Inc., Version 5.0.0). The mean values \pm SEM were calculated for each parameter. Level of significance was kept at $p<0.05$.

\section{RESULTS}

\section{Yield of the extract}

The yield of the extracts was calculated as $3.2 \%$ and $2.6 \%$ respectively for both the MECF and AECF.

Further preliminary phytochemical tests were performed separately as per the method described by Khandelwal, (1996) and revealed the presence of alkaloids, terpenoids, saponins, tannins, carbonyl, phlobatanin, and steroids in MECF whereas alkaloids, flavonoids, saponin, reducing sugar are more prominently present in AECF.

\section{Acute oral toxicity}

Acute oral toxicity studies revealed the non-toxic nature of both of the extracts and did not show any sign and symptoms of toxicity and mortality up to $2000 \mathrm{mg} / \mathrm{kg}$ dose.

\section{Effect of AD feeding for 21 days on lipid profile}

SD rats were fed with $\mathrm{AD}$ diet for 30 days to find out induction of hyperlipidemia. Blood samples were collected and analyzed on every 7 th day till the 30 th day from both AD fed and normal diet fed groups.

The optimum levels of TC and TG were seen on 21st day in comparison to normal pellet diet group fed animals. On 30th day there was not much significant rise in TC and TG in comparison to 21 st day. For 7 th and 14th day rats did not show much significant increase in serum lipid profile (Table 1). 
Table 1. Effect of AD feeding for 21 days on lipid profile.

\begin{tabular}{|c|c|c|c|}
\hline \multicolumn{2}{|c|}{ Duration } & \multirow{2}{*}{$\begin{array}{c}\text { Normal group } \\
73.3 \pm 5.5\end{array}$} & \multirow{2}{*}{$\begin{array}{c}\text { AD group } \\
129.8 \pm 5.6^{* *}\end{array}$} \\
\hline $7^{\text {th }}$ & $\mathrm{TC}(\mathrm{mg} / \mathrm{dl})$ & & \\
\hline day & TG (mg/dl) & $77.23 \pm 4.779$ & $155.5 \pm 8.46^{* *}$ \\
\hline \multirow{2}{*}{$\begin{array}{l}14^{\text {th }} \\
\text { day }\end{array}$} & $\mathrm{TC}(\mathrm{mg} / \mathrm{dl}$ & $77.00 \pm 4.524$ & $138.5 \pm 12.77^{* *}$ \\
\hline & $\mathrm{TG}(\mathrm{mg} / \mathrm{dl})$ & $77.90 \pm 7.912$ & $167.25 \pm 8.23^{* *}$ \\
\hline \multirow{2}{*}{$\begin{array}{l}21^{\text {th }} \\
\text { day }\end{array}$} & $\mathrm{TC}(\mathrm{mg} / \mathrm{dl})$ & $74.80 \pm 3.669$ & $151.5 \pm 6.269^{* *}$ \\
\hline & $\mathrm{TG}(\mathrm{mg} / \mathrm{dl})$ & $78.07 \pm 8.050$ & $170.5 \pm 4.905^{* * *}$ \\
\hline \multirow{2}{*}{$\begin{array}{l}30^{\text {th }} \\
\text { day }\end{array}$} & $\mathrm{TC}(\mathrm{mg} / \mathrm{dl})$ & $75.13 \pm 4.779$ & $156.5 \pm 3.975$ \\
\hline & TG (mg/dl) & $77.83 \pm 6.273$ & $164.5 \pm 5.90^{* * *}$ \\
\hline
\end{tabular}

\section{Effect of treatments on serum lipids}

The values obtained for the different serum parameters tested in the present study and was depicted in Table 2. In comparison to normal control group, rats fed with AD for 21 days had highly significant increase in all serum parameters TC, TG, non-HDL, TC:HDL and AI (p $<0.001$ ) and decrease in HDL levels when compared with control animals. Treated with Atorvasatin $(10 \mathrm{mg} / \mathrm{kg}$ body weight p.o) showed significant decrease in elevated TC, TG, Non-HDL, TC/HDL ratio and AI, with significant increase in HDL $(\mathrm{p}<0.001)$ as compared with the atherogenic diet induce rats whereas the animals treated with the extracts of CF leaf shows the significant effects on lipid profile.

MECF and AECF (200 mg/kg p.o) showed significant decrease in elevated TC, TG, Non-HDL, TC/HDL ratio and AI with significant of $(\mathrm{p}<0.001)$, with significant increase in HDL $(\mathrm{p}<0.05)$ but both the extracts at $400 \mathrm{mg} / \mathrm{kg}$ p.o dose level, do not show any significant effect on TG, HDL levels when compared with normal control group (Table 2).

The same trend was followed in case of treatments when compared with AD induced group. MECF and AECF showed significant decrease in elevated TC, TG, Non-HDL, TC/HDL ratio and AI with significant of $(p<0.001)$ but were dose dependent manner. Furthermore, AECF at dose of $400 \mathrm{mg} / \mathrm{kg}$ showed more effective result in elevated TC (126.5 $\mathrm{mg} / \mathrm{kg})$, TG (70.48 mg/kg), Non-HDL (89.36 mg/kg), TC/HDL ratio $(3.413 \mathrm{mg} / \mathrm{kg})$ and AI $(0.992 \mathrm{mg} / \mathrm{kg})$ than MECF in different biochemical estimations (Table 2).

Both the treatments showed effective results on various serum lipids when compared with the standard Atorvastatin $(10 \mathrm{mg} / \mathrm{kg}$, p.o $)$ drug but the effects were less than the standard.

Even though the effects were dose dependent but in comparison, AECF $(400 \mathrm{mg} / \mathrm{kg}$ ) showed more significant results than others (Table 2). 
Table 2. Effect of various extracts of MECF and CAECF on Atherogenic Diet induce rats and Atorvastatin $(10 \mathrm{mg} / \mathrm{kg}, \mathrm{p} . \mathrm{o})$ on serum lipids.

\begin{tabular}{|c|c|c|c|c|c|c|c|}
\hline Parameters & $\begin{array}{l}\text { Normal } \\
\text { Control }\end{array}$ & $\begin{array}{c}\text { AD } \\
\text { diet } \\
\text { control }\end{array}$ & Std drug & $\begin{array}{c}\text { MECF } \\
200 \mathrm{mg} / \mathrm{kg}\end{array}$ & $\begin{array}{c}\text { MECF } \\
400 \mathrm{mg} / \mathrm{kg}\end{array}$ & $\begin{array}{c}\text { AECF } \\
200 \mathrm{mg} / \mathrm{kg}\end{array}$ & $\begin{array}{c}\text { AECF } \\
400 \mathrm{mg} / \mathrm{kg}\end{array}$ \\
\hline TC $f$ & $\begin{array}{c}90.80 \pm \\
4.094\end{array}$ & $\begin{array}{l}172.2 \pm \\
1.577^{\mathrm{c}}\end{array}$ & $\begin{array}{c}98.65 \pm \\
2.867^{\mathrm{r}}\end{array}$ & $\begin{array}{c}160.9 \pm \\
1.405^{\mathrm{cqz}}\end{array}$ & $\begin{array}{l}150.6 \pm \\
2.188^{\mathrm{crz}}\end{array}$ & $\begin{array}{l}167.1 \pm \\
1.294^{\mathrm{cz}}\end{array}$ & $\begin{array}{l}126.5 \pm \\
2.339^{\mathrm{crz}}\end{array}$ \\
\hline TG $f$ & $\begin{array}{c}78.30 \pm \\
3.887\end{array}$ & $\begin{array}{l}175.7 \pm \\
4.449^{c}\end{array}$ & $\begin{array}{l}66.95 \pm \\
4.584^{\mathrm{r}}\end{array}$ & $\begin{array}{l}164.6 \pm \\
6.936^{\mathrm{cz}}\end{array}$ & $\begin{array}{l}87.13 \pm \\
4.168^{\mathrm{rx}}\end{array}$ & $\begin{array}{c}152.3 \pm \\
2.915^{\mathrm{cqz}}\end{array}$ & $\begin{array}{l}70.48 \pm \\
4.266^{\mathrm{r}}\end{array}$ \\
\hline HDL $f$ & $\begin{array}{l}35.77 \pm \\
0.5384\end{array}$ & $\begin{array}{l}24.34 \pm \\
0.5810^{\mathrm{c}}\end{array}$ & $\begin{array}{c}39.95 \pm \\
0.3991^{\mathrm{cr}}\end{array}$ & $\begin{array}{c}33.06 \pm \\
0.6949^{\text {brz }}\end{array}$ & $\begin{array}{l}35.28 \pm \\
0.592^{\mathrm{rz}}\end{array}$ & $\begin{array}{l}33.16^{ \pm} \\
0.515^{\text {arz }}\end{array}$ & $\begin{array}{l}37.13 \pm \\
0.530^{\mathrm{rz}}\end{array}$ \\
\hline Non HDL $f$ & $\begin{array}{c}55.03 \pm \\
3.872\end{array}$ & $\begin{array}{l}150.9 \pm \\
2.958^{\mathrm{c}}\end{array}$ & $\begin{array}{l}58.71 \pm \\
2.597^{\mathrm{r}}\end{array}$ & $\begin{array}{l}127.8 \pm \\
1.723^{\mathrm{crz}}\end{array}$ & $\begin{array}{l}115.3 \pm \\
1.959^{\mathrm{crz}}\end{array}$ & $\begin{array}{l}133.9 \pm \\
1.577^{\mathrm{crz}}\end{array}$ & $\begin{array}{l}89.36 \pm \\
2.64^{\mathrm{crz}}\end{array}$ \\
\hline $\mathrm{TC}: \mathrm{HDL}$ & $\begin{array}{c}2.934 \pm \\
0.105\end{array}$ & $\begin{array}{l}7.102 \pm \\
0.219^{c}\end{array}$ & $\begin{array}{c}2.508 \pm \\
0.093^{\mathrm{r}}\end{array}$ & $\begin{array}{l}4.878 \pm \\
0.118^{\mathrm{crz}}\end{array}$ & $\begin{array}{l}4.271 \pm \\
0.066^{\mathrm{crz}}\end{array}$ & $\begin{array}{l}5.046 \pm \\
0.100^{\mathrm{crz}}\end{array}$ & $\begin{array}{l}3.413 \pm \\
0.095^{\mathrm{arz}}\end{array}$ \\
\hline AI $\Delta$ & $\begin{array}{c}0.799 \pm \\
0.028\end{array}$ & $\begin{array}{c}2.688 \pm \\
0.011^{\mathrm{c}}\end{array}$ & $\begin{array}{c}0.7025 \pm \\
0.008^{r}\end{array}$ & $\begin{array}{c}1.63 \pm \\
0.007^{\mathrm{crz}}\end{array}$ & $\begin{array}{c}1.28 \pm \\
0.078^{\mathrm{crz}}\end{array}$ & $\begin{array}{c}1.403 \pm \\
0.016^{\mathrm{crz}}\end{array}$ & $\begin{array}{c}0.992 \pm \\
0.070^{\text {arz }}\end{array}$ \\
\hline
\end{tabular}

$f \mathrm{mg} / \mathrm{dl}, \Delta$ units.

Values are mean $\pm \operatorname{SEM}(\mathrm{n}=6)$

p values: $\mathrm{a}<0.05, \mathrm{~b}<0.01, \mathrm{c}<0.001$, as compared with Normal control; $\mathrm{p}<0.05, \mathrm{q}<0.01, \mathrm{r}<0.001$, as compared with AD diet, $\mathrm{x}<0.05, \mathrm{y}<0.01, \mathrm{z}<0.001$, as compared with Atorvastatin (by one-way ANOVA followed by Dunnett multiple comparison test)

\section{Effect of treatments on liver lipid per oxidation (LPO)}

Compared to normal control group, rats fed with AD diet had highly significant increase in LPO levels $(\mathrm{p}<0.001)$ whereas the Atorvastatin control $(10 \mathrm{mg} / \mathrm{kg} \mathrm{b.w}$, p.o $)$ showed significant decrease in LPO level $(\mathrm{p}<0.001)$ when compared with AD control. Furthermore the leaf extracts of MECF and AECF when compared with normal $(3.060 \mathrm{mg} / \mathrm{kg}), \mathrm{AD}$ control group $(6.220 \mathrm{mg} / \mathrm{kg})$ and standard Atorvastatin drug $(2.887 \mathrm{mg} / \mathrm{kg})$, both of the extracts showed significant decrease of LPO level but the effects were dose dependent. AECF (3.100 $\mathrm{mg} / \mathrm{kg})$ showed more significant results as compared to MECF $(3.483 \mathrm{mg} / \mathrm{kg})$ at the dose of $400 \mathrm{mg} / \mathrm{kg}$ which was almost closed to Atorvastatin drug (Fig. 1).

\section{Histopathology}

Histopathology of the liver and coronary artery for all the groups of rats has carried out. Rats fed normal control diet showed normal hepatocyte architecture such as healthy nucleus and parenchymal structure [Fig. 2(a)]. AD fed animals showed condition called fatty liver with peripheral nucleus and altered hepatocyte architecture and several fat globules were seen [Fig. 2 (b)]. Various doses of CF leaf extract showed reduction in fat globules in hepatocytes. But animals treated with Atorvastatin and $4000 \mathrm{mg} / \mathrm{kg}$ of MECF and AECF restored the normal architecture and no fatty liver changes were found. 
Sections of coronary artery studied in rats fed with normal diet fed rats did not show any of these changes [Fig. 3 (a)] whereas AD fed rats showed swollen endothelial cells in the intima of coronary artery and there was often a splitting of the elastica interna seen [Fig. 3 (b)]. Thereafter Atorvastatin and CF extracts (MECF and AECF at dose of $400 \mathrm{mg} / \mathrm{kg}$ ) treated rats showed normal histology of coronary arteries without any changes [Fig. 3(c) and (d, e)].

Fig. 1. Effect of Cassia fistula Leaf on Atherogenic Diet induce rats at the dose of Methonolic extract $200 \mathrm{mg} / \mathrm{kg}$ and $400 \mathrm{mg} / \mathrm{kg}$, Aqueous extract $200 \mathrm{mg} / \mathrm{kg}$ and $400 \mathrm{mg} / \mathrm{kg}$ and Atorvastatin $(10 \mathrm{mg} / \mathrm{kg}, \mathrm{p} . \mathrm{o})$ on Lipid peroxidation.

\section{Lipid peroxidation}

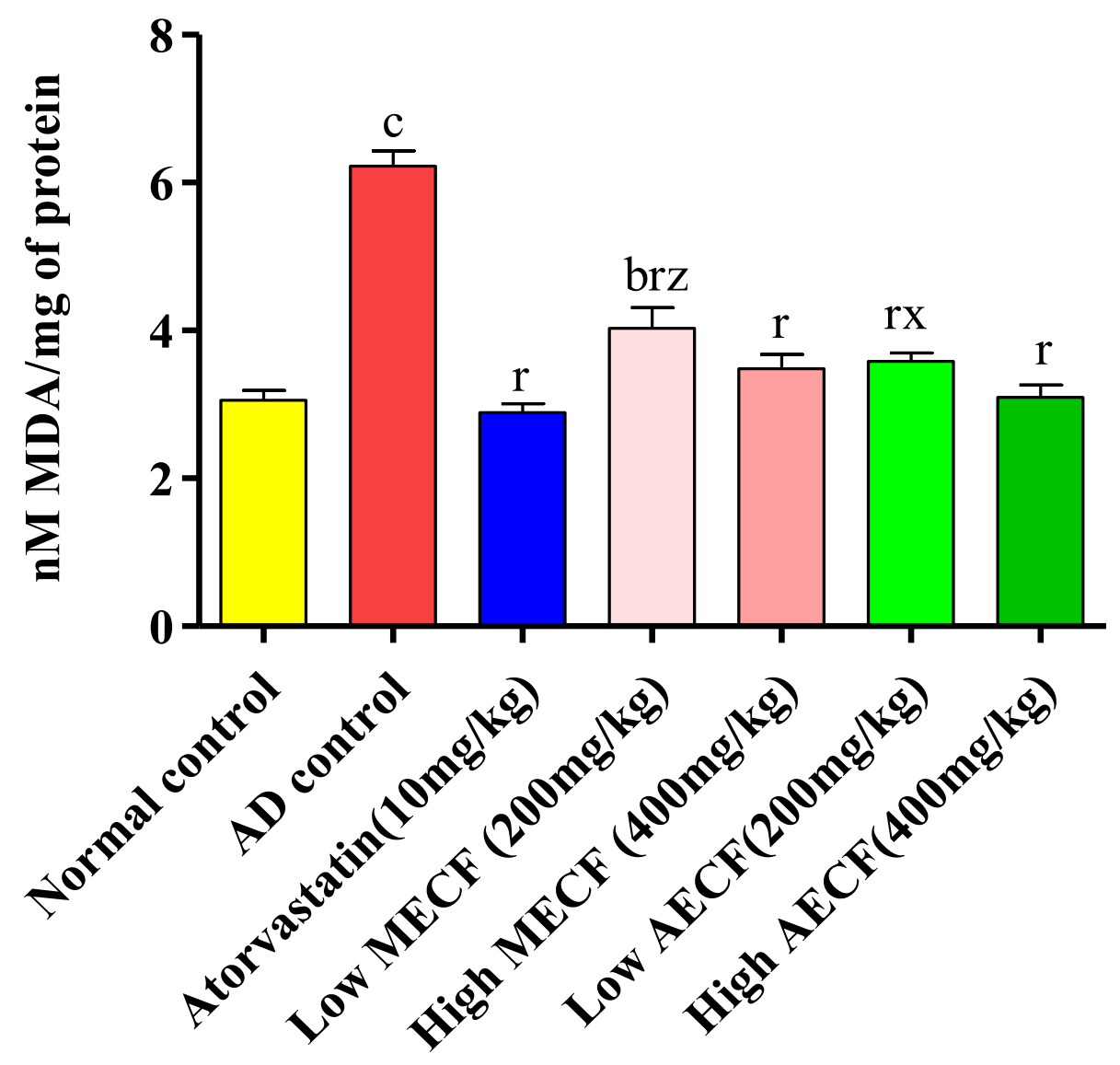

\section{Experimental groups}

$f \mathrm{mg} / \mathrm{dl}, \Delta$ units. Values are mean $\pm \operatorname{SEM}(\mathrm{n}=6)$

p values: $\mathrm{a}<0.05, \mathrm{~b}<0.01, \mathrm{c}<0.001$, as compared with Normal control; $\mathrm{p}<0.05, \mathrm{q}<0.01, \mathrm{r}<0.001$, as compared with $\mathrm{AD}$ diet, $\mathrm{x}<0.05, \mathrm{y}<0.01, \mathrm{z}<0.001$, as compared with Atorvastatin (by one-way ANOVA followed by Dunnett multiple comparison test) 


\section{HISTOPATHOLOGY OF LIVER}

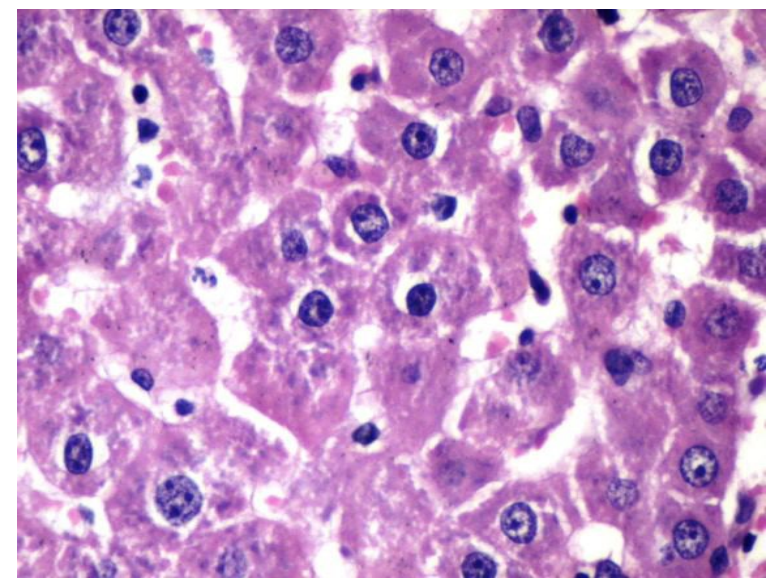

Fig. 2(a). Liver section (40X) of normal fed diet showing rat showing normal hepatocyte architecture located nucleus.

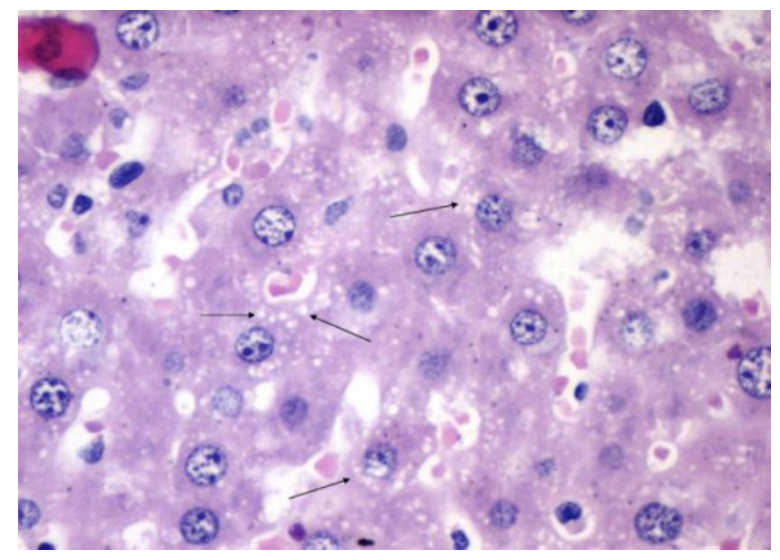

Fig. 2(b). Liver section (40X) of AD fed rat fatty liver with peripheral.

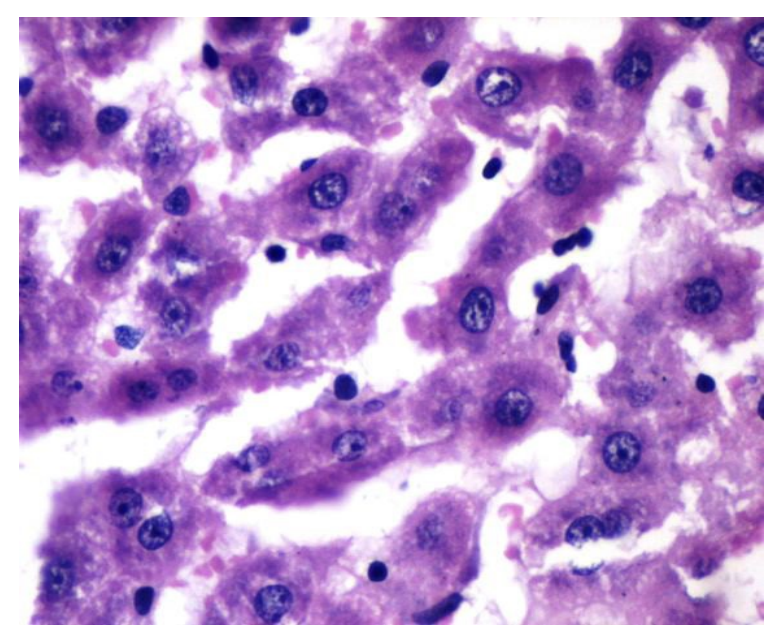

Fig. 2(c). Liver section (40X) of Atorva $-400 \mathrm{mg} / \mathrm{kg}$ statin treated rat showing normal hepatocytes. 


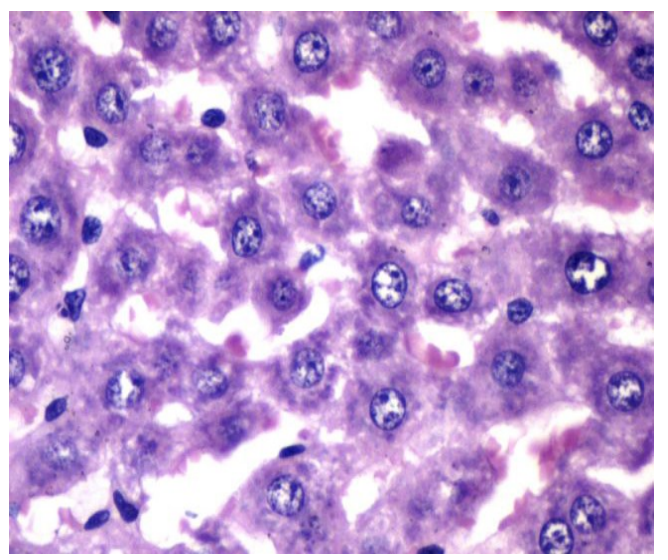

Fig. 2(d). Liver section (40X) of MECF showing normal hepatocyte architecture.

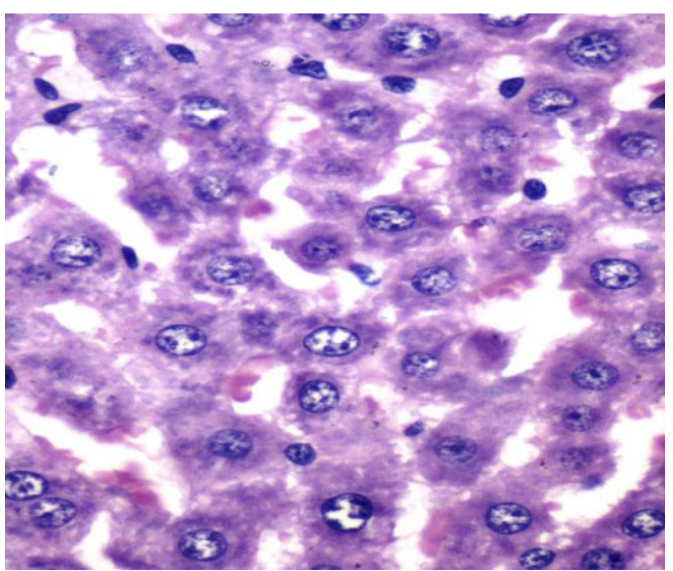

Fig. 2(e). Liver section (40X) of AECF $400 \mathrm{mg} / \mathrm{kg}$ showing normal hepatocyte architecture.

\section{HISTO PATHOLOGY OF CARONARY ARTERY}

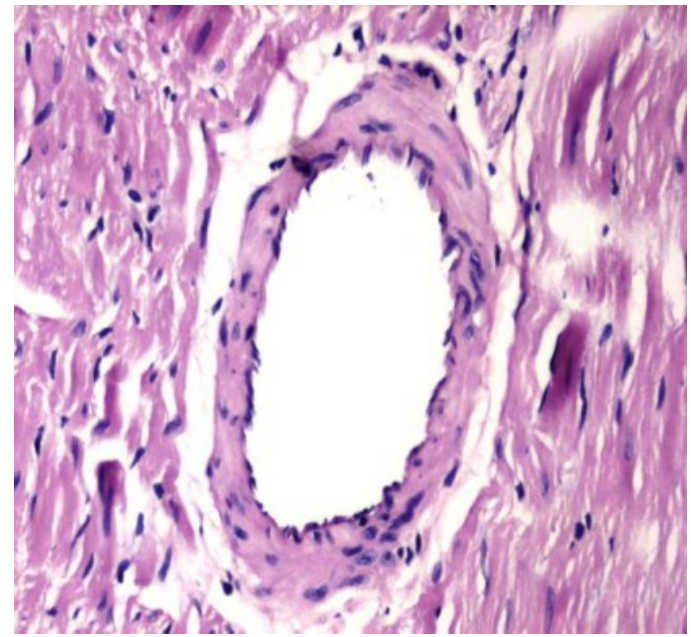

Fig. 3(a). Coronary artery section (20X) Showing norman intima. 


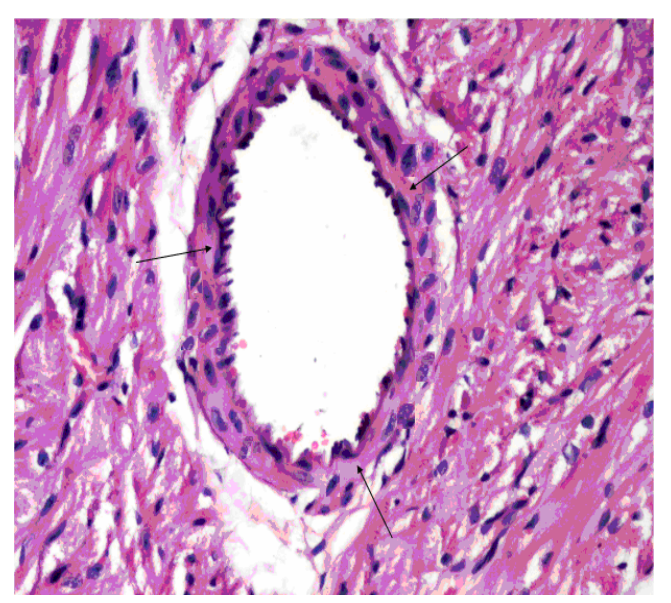

Fig. 3(b). Coronary artery section 20X AD fed rat showing swollen endothelial Cell in intima with splitting of the elastic intima.

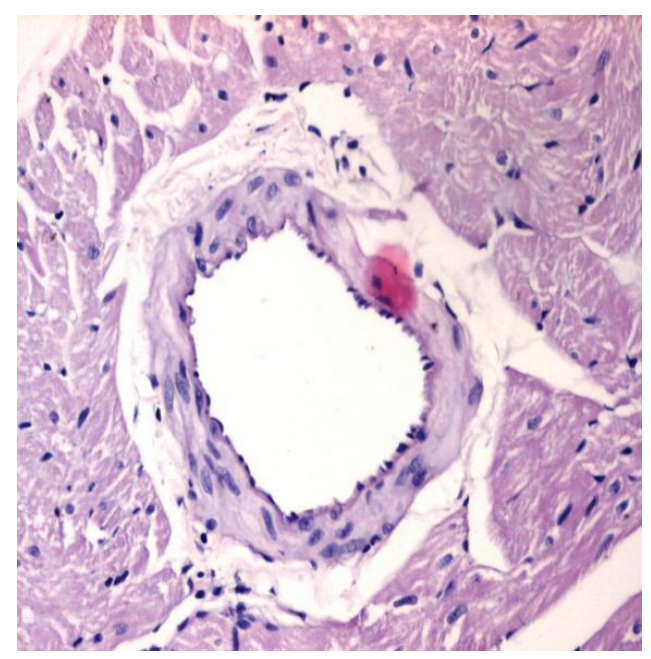

Fig. 3(c). Coronary artery section $20 \mathrm{X}$ of Atorvastatin treated rat showing normal intima.

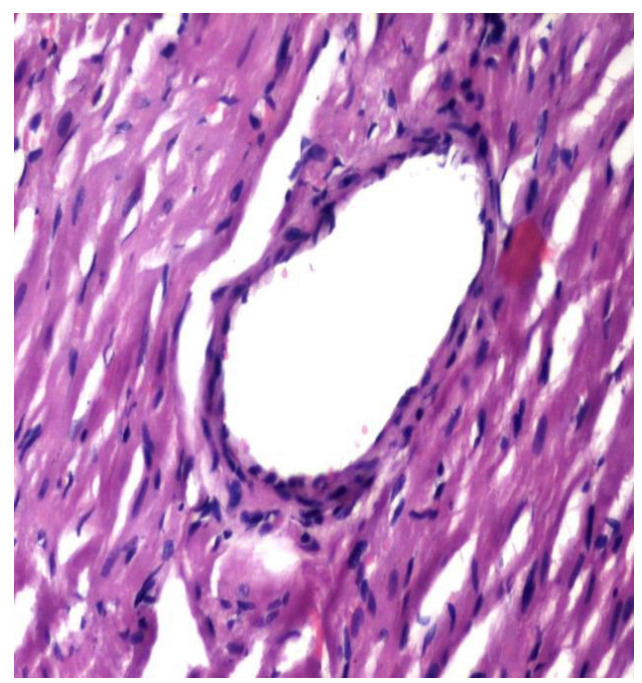

Fig. 3 (d). Coronary artery section 20X of rat treated with MECF $400 \mathrm{mg} / \mathrm{kg}$ showing normal intima. 


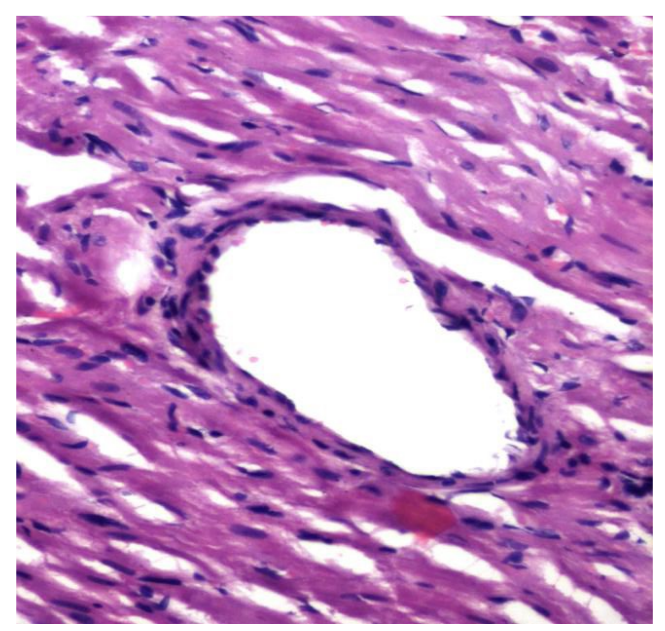

Fig. 3(e). Coronary artery section $20 X$ of rat treated with AECF $400 \mathrm{mg} / \mathrm{kg}$ showing normal intima.

\section{DISCUSSION}

Diet containing SFA (Lard) increases the activity of HMG CoA-reductase, the ratedetermining enzyme in cholesterol biosynthesis; this may be due to higher availability of acetyl CoA, which stimulates the cholesterogenesis rate. Moreover, this could be associated with a down regulation in LDL receptors by the cholesterol in the diet, which could also explain the elevation of serum LDL cholesterol levels or non-HDL levels either by changing hepatic LDL receptor activity, the LDL production rate or both (Jadhav and Bhutani, 2002). The activity of CETP, a key enzyme in reverse cholesterol transport and HDL metabolism increases in HFD and mediates the transfer of cholesteryl esters from HDL cholesterol to TG rich particles in exchange for TG. This leads to increased plasma concentrations of TGs \& decreased concentrations of HDL cholesterol (Van Aalst-Cohen et al, 2004).

In the present study rats fed with $\mathrm{AD}$ showed significant increase in $\mathrm{TC}, \mathrm{TG}$ and nonHDL, TC: HDL and AI values (Table 2) confirming that cholesterol feeding induced hypercholesteremia experimentally. When compared to AD treated group, treatment of experimentally induced hyperlipidemic rats with MECF and AECF at the dose of $400 \mathrm{mg} / \mathrm{kg}$ showed highly significant decrease of non-HDL, TC: HDL and AI $(p<0.001)$ TC showed significant of $(p<0.05)$ whereas TG does not showed significant, with significant increase in HDL $(p<0.001)$ than the lower dose of $200 \mathrm{mg} / \mathrm{kg}$.

These values were almost equivalent to our reference standard Atorvastatin $(10 \mathrm{mg} / \mathrm{kg})$ used as positive control. High levels of TC and most importantly, non-HDL cholesterol are the predictors of atherosclerosis. Decrease in TC, TG, AI, LPO and increase in HDL levels in the present study showed beneficial effect of CF Leaf against atherogenesis and are possibly due to its effects on excretion of cholesterol or reducing the absorption of cholesterol or both which was similar as reported by Mathur et al. 1996. Earlier study revealed 1\% elevation of HDL results in an approximately $2 \%$ reduction in CHD (Talbert, 2008) events as HDL have a protective effect against cardiovascular diseases.

MECF and AECF leaf (200 mg/kg and $400 \mathrm{mg} / \mathrm{kg}$ ) showed significant increase in HDL $(\mathrm{p}<0.001)$. This is also evident from TC: HDL ratio where various groups are showing a trend towards decrease in TC: HDL levels signifying the beneficial effect of CF leaf on HDL showed by greater protection against atherosclerosis as the AI value was found to be very less compared to AD control group (Table 2). 
It has been reported that HFD brings about remarkable modifications in the antioxidant defense mechanisms of rat tissues by increasing the process of LPO, which plays an important role in oxidative stress of biological systems (Liu et al., 2008). In the present study MECF and AECF $(400 \mathrm{mg} / \mathrm{kg})$ showed highly significant reduction in LPO $(\mathrm{p}<0.001)$ levels compared to AD group (Table 1).

This effect can be attributed to many phenolic constituents in CF leaf which has the ability to strongly inhibit LPO and high concentration of flavonoids which are potent antioxidants and free radical scavengers (Theeshan et al., 2005). As per previous studies conducted on antioxidant properties of Cassia fistula leaves it has been seen that CF leaf reduced the levels of LPO and concomitantly increased the levels and activities of super oxide dismutase (SOD), Catalase and Glutathione enzyme. Therefore it was clear that decrease in LPO levels as in the present study will also lead to increase in antioxidant enzymes like SOD, Catalase and Glutathione levels (Kannamapalli et al., 2010) and finally histopathology study supports the same.

\section{CONCLUSION}

MECF and AECF showed dose dependent activities on various serum lipids and reduced LPO levels significantly. Furthermore the better activities has revealed by the AECF at dose of $400 \mathrm{mg} / \mathrm{kg}$. Hence the present investigation has suggested the significant protection in lowering TC, TG, non-HDL, TC: HDL ratio, AI, LPO and increasing HDL levels by the $\mathrm{CF}$ leaf extract. The results finally indicate $\mathrm{CF}$ has the protective as well as preventive action against $\mathrm{AD}$ induced hyperlipidemia and atherogenesis.

\section{References}

[1] Allain CC, Poon LS, Chan CS, Richmond W, Fu PC. Enzymatic determination of total serum cholesterol. Clin Chem 1974; 20: 470-475.

[2] Arun SL, Kumar T, Balakrishna M, Sadashivan P. Hypolipidemic effect of Coriandrum sativam L. in triton-induced hyperlipidemic rats. Indian J. Exp. Bio. 2004; 42: 909-912.

[3] Bhakta T, Banerjee S, Mandal SC, Maity TK, Saha BP, Pal M. Hepatoprotective activity of Cassia fistula leaf extract. Phytomedicine 2001; 8: 220-224.

[4] Burstein M, Scholnick HR, Morfin R. Rapid method for isolation of lipoproteins from human serum by precipitation with polyanions. J Lipid Res 1970; 11: 583-595.

[5] Das K. Phytochemical evaluation and comparative antibiocide efficacy of Aqueous, Ethanolic and equal mixture of aqueous and ethanolic (1:1) bark extract of Lannea coromandelica L. procured from Eastern region of India. International Letters of Natural Sciences 2014; 21: 21-31.

[6] Dutta A, De B. Seasonal variation in the content of sennosides and rhein in leaves and pods of Cassia fistula. Indian J. Pharmacol. Sci. 1998; 60: 388-390.

[7] Duraipandivan V, Ignacimuthu S. Antibacterial and antifungal activity of Cassia fistula L. An ethnomedicinal plant. Journal of Ethnopharmacology 2007; 112: 590-594. 
[8] el-Saadany SS, el-Massry RA, Labib SM, Sitohy MZ. The biochemical role and hypocholesterolaemic potential of the legume Cassia fistula in hypercholesterolnic rats. Nahrung 1991; 35: 807-835.

[9] Fossati P, Prencipe L. Serum triglycerides determined colorimetrically with an enzyme that produces hydrogen peroxide. Clin Chem 1982; 28: 2077-2080.

[10] Gupta U, Jain GC. Study of Hypolipidemic Activity of Cassia fistula. Legume in rats. Asian J Exp Sci 2009; 23: 241-248.

[11] Harikumar K, Abdul Althaf S, Kishore kumar B, Ramunaik M, Suvarna CH. A Review on Hyperlipidemic. International Journal of Novel Trends in Pharmaceutical Sciences 2013; 3(4): 59-71.

[12] Hirunpanich V, Utaipat A, Morales NP, Bunyapraphatsara N, SatoH, Herunsale A, et al. Hypocholesterolemic and antioxidant effects of aqueous extracts from the dried calyx of Hibiscus sabdariffa L in hypercholesterolemic rats. J Ethnopharmacol 2006; 103: 252260.

[13] Ilavarasan R, Mallika M, Venkataraman S. Antiinflammatory and antioxidant activities of Cassia fistula Linn. Bark extracts. Afr. J. Trad. CAM 2005; 2 (1): 70-85.

[14] Jadhav HR, Bhutani KK. Antioxidant properties of Indian Medicinal plants. Phytother. Res 2002; 16: $771-773$.

[15] Kannamapalli P, Chandrasekaran VR, Kupannan G, Sivanesan K. Protective effect of Cassia fistula Linn. on diethylnitrosamine induced hepatocellular damage and oxidative stress in ethanol pretreated rats. Biol Res 2010; 43: 113-125.

[16] Khandelwal KR. Practical pharmacognosy techniques and experiments. 3rd ed. Pune: Nirali Prakashan 1996.

[17] Kirtikar KR, Basu BD. Indian Medicinal Plants, Val. II, Second edition published by Lalit Mohan Basu, Allahbad 1933.

[18] Liu X, Cui C, Zhao M, Wang J, Luo W, Yang B, et al. Identification of phenolics in the fruit of emblica (Phyllanthus emblica L.) and their antioxidant activities. Food Chem 2008; 109: 909-915.

[19] Luximon-Ramma A, Bahorun T, Soobrattee MA, Aruoma OI. Antioxidant activities of phenolic, proanthocyanidin, and flavonoid components in extracts of Cassia fistula. $J$ Agric Food Chem 2002; 50(18): 5042-5047.

[20] Mathur R, Sharma A, Dixit VP, Varma M. Hypolipidaemic effect of fruit juice of Emblica officinalis in cholesterol-fed rabbits. J Ethnopharmacol 1996; 50: 61-68.

[21] Ohkawa H, Ohishi N, Yagi K. Assay of lipid peroxidases in animal tissues by thiobarbituric acid reaction. Biochem 1979; 95:351-358.

[22] Parini P, Angelin B, Stavreus-Evers A, Freyschuss B, Eriksson H, Rudling M. Biphasic effects of the natural estrogen 17 beta-estradiol on hepatic cholesterol metabolism in intact female rats. Arterioscler Thromb Vasc Biol 2000; 20:1817-1823.

[23] Sheikh NW, Patel RD, Upwar NI, Mahobia NK, Seth MV, Panchal UR. Analgesic study of methyl alcohol extract of Cassia fistula Pod, J. Pharmacy Res 2010; 3(9): 2218-2219. 
[24] Talbert RL. Hyperlipidemia. In: Dipiro JT, Talbert RL, Yee GC, Matzke GR, Wells BG, Posey LM, editors. Pharmacotherapy: a pathophysiologic approach. 7th ed. New York: McGraw-Hill; 2008. p. 385-407.

[25] Theeshan B, Vidushi S, Neergheen, Okezie I, Aruoma. Phytochemical constituents of Cassia fistula. Afr. J. Biotechnol 2005; 4 (13): 1530-1540.

[26] Van Aalst-Cohen ES, Trip MD, Vissers MN, Rodenburg J, Kastelein JJ. Metabolic diseases, Clinical, diagnostic and therapeutic aspects of (inherited) hypercholesterolemia. Drug Discov Today Dis Mech 2004; 1:165-170.

[27] Xu L, Liu Y, Wang T, Qi Y, Han X, Xu Y, et al. Development and validation of a sensitive and rapid non-aqueous LC-ESI-MS/MS method for measurement of diosgenin in the plasma of normal and hyperlipidemic rats: A comparative study. J Chrom B 2009; 877: 1530-1536. 